\title{
Studies of Phosphorus Gaussian Profile Emitter Silicon Solar Cells
}

\author{
N. Stem ${ }^{*}$, M. Cid ${ }^{* *}$ \\ Laboratório de Microeletrônica, Depto. de Engenharia de Sistemas Eletrônicos \\ Escola Politécnica da Universidade de São Paulo, C.P. 61548 \\ 05424-970 São Paulo - SP, Brazil
}

Received: January 30, 2001; Revised: April 4, 2001

\begin{abstract}
Considering recent modifications on n-type highly doped silicon parameters, an emitter optimization was made based on one-dimensional models with analytical solutions. In order to get good accuracy, a fifth order approximation has been considered. Two kinds of emitters, homogeneous and non-homogeneous, with phosphorus Gaussian profile emitter solar cells were optimized. According to our results: homogeneous emitter solar cells show their maximum efficiencies $(\eta \cong 21.60-21.74 \%)$ with doping levels $\mathrm{N}_{\mathrm{s}}=1 \times 10^{19}-5 \times 10^{18}\left(\mathrm{~cm}^{-3}\right)$ and $(1.2-2.0) \mu \mathrm{m}$ emitter thickness range. Non-homogeneous emitter solar cells provide a slightly higher efficiency $(\eta=21.82-21.92 \%)$, with $\mathrm{N}_{\mathrm{s}}=1 \times 10^{20}\left(\mathrm{~cm}^{-3}\right)$ with $2.0 \mu \mathrm{m}$ thickness under metal-contacted surface and $\mathrm{N}_{\mathrm{S}}=1 \times 10^{19}-5 \times 10^{18}\left(\mathrm{~cm}^{-3}\right)$ with $(1.2-2.0) \mu \mathrm{m}$ thickness range, (sheet resistance range 90-100 $\Omega / \square$ ) under passivated surface. Although non-homogeneous emitter solar cells have a higher efficiency than homogeneous emitter ones, the required technology is more complex and their overall interest for practical applications is questionable.
\end{abstract}

Keywords: solar cell efficiencies-1, homogeneous emitter-2, non-homogeneous emitter-3, Gaussian profile-4

\section{Introduction}

In order to improve solar cell efficiencies, several theoretical optimizations of emitter region have been proposed throughout the years. In the eighties a breakthrough occurred in the emitter design philosophy aimed to the development of efficient silicon solar cells ${ }^{1}$. It was shown that the best emitters should be thick and moderately doped. According to A. Cuevas and M. Balbuena ${ }^{2}$, solar cells with homogeneous emitters with $\mathrm{N}_{\mathrm{s}}=1 \times 10^{19}-5 \times 10^{18}\left(\mathrm{~cm}^{-3}\right)$ and thickness of 1.0-2.0 $(\mu \mathrm{m})$ are the best ones. In 1990, based on these works, A. Aberle et al. optimized LDD (locally deep diffused) and homogeneous emitters, getting the conclusion that LDD emitters are better than homogeneous ones $^{3}$. Despite the required technology to process these emitters are complex, non-homogeneous emitters has still been adopted in research laboratories, and they are found in the solar cells with record efficiencies. However a question must be asked: are non-homogeneous emitters significantly better? Moreover, recent modifications of highly doped n-type parameters made new theoretical optimizations of emitters imperative. Therefore, this work has two important motivations: comparison between the two kinds of emitters and the necessity of optimizing emitters considering updated parameters ${ }^{4}$. Theoretical models with analytical solutions have been used to study $\mathrm{n}^{+}$emitter region $^{5,6}$. Admitting a Gaussian profile, two kinds of emitters, homogeneous and non-homogeneous, were optimized and compared considering different kinds of surfaces, emitter doping levels and thicknesses. In order to calculate theoretical solar cell efficiency, a complete $\mathrm{n}^{+} \mathrm{pp}^{+}$structure was considered. To point out the effect of emitter optimization, the base and $\mathrm{p}^{+}$region parameters have been considered constant. The base region has been admitted to have a resistivity of $\rho=1 \Omega . \mathrm{cm}$, a diffusion length $1350 \mu \mathrm{m}$ and a thickness $290 \mu \mathrm{m}$. A structure with back surface field (BSF) has been also considered, adding a uniform profile and a rear surface recombination velocity $S_{n}=200(\mathrm{~cm} / \mathrm{s})^{7}$. The photon absorption within the BSF region was neglected. Neither light trapping effects nor surface reflection 
have been taken into account. The metal grid shadowing factor was assumed as $\mathrm{F}_{\mathrm{m}}=3(\%)$. The output parameters (short-circuit density $\left(\mathrm{J}_{\mathrm{sc}}\right)$, open-circuit voltage $\left(\mathrm{V}_{\mathrm{oc}}\right)$ and efficiency $(\eta)$ ) were calculated using well-known relationships $^{8}$. The solar cells efficiencies were obtained using the fill factor given by Green's expression? .

\section{Theoretical Emitter Model}

The transport equations for minority carriers in an ntype emitter under steady condition are:

$$
\begin{aligned}
& J_{p}=q \mu_{p} p E_{p}-q D_{p} \frac{d p}{d x} \\
& \frac{1}{q} \frac{d J_{p}}{d x}=G-\frac{1}{\tau_{p}}\left(p-p_{0}\right)
\end{aligned}
$$

where, $\mathrm{J}_{\mathrm{p}}$ is the minority carriers current density; $\mu_{\mathrm{p}}$, minority carrier mobility; $p$, minority carrier concentration; $\mathrm{p}_{\mathrm{o}}$, minority carrier equilibrium concentration; $\mathrm{E}_{\mathrm{p}}$, electric field; q, Coulomb charge; $\mathrm{D}_{\mathrm{p}}$, diffusion coefficient; $\mathrm{G}$, carrier generation and $\tau_{\mathrm{p}}$, minority carrier lifetime.

As it is well known, some effects such as band gap narrowing, Fermi level degeneracy and changes of behavior of minority carrier lifetime and mobility occur when a region is highly doped, as for solar cell emitters. As the parameters, band gap narrowing, minority carrier mobility and lifetime, are position dependent, an analytical solution to Eqs. (1) and (2) is required. Table 1 shows the internal parameters and expressions used for the emitter model.

Considering the apparent band gap notation $\Delta E_{g}^{a p p}$, the minority carrier equilibrium concentration $\left(\mathrm{p}_{\mathrm{o}}\right)$ can be written according to Eq. (3).

$$
p_{0}(x)=\frac{n_{i o}^{2}}{N_{d}(x)} \exp \left(\frac{\Delta E_{g}^{a p p}(x)}{k T}\right)
$$

Table 1. Expressions and parameters that were used in the theoretical emitter optimization for $\mathrm{n}+$ region.

$$
\begin{aligned}
& n_{i}{ }^{2}(300 \mathrm{~K})=1 \times 10^{20}\left(\mathrm{~cm}^{-6}\right) \\
& \tau_{p}^{-1}(x)=50+2 \times 10^{-13} N_{d}(x)+2.2 \times 10^{-31} N_{d}^{2}(x)\left(\mathrm{s}^{-1}\right) \\
& \mu_{p}(x)=\frac{315}{1+\left(\frac{N_{d}(x)}{1 \times 10^{17}}\right)^{0.9}}+155\left(\mathrm{~cm}^{-3}\right) \\
& \Delta E_{g}^{a p p}=0(\mathrm{eV}) \text { when } \mathrm{N}_{\mathrm{d}}<1.4 \times 10^{17}\left(\mathrm{~cm}^{-3}\right) \\
& \Delta E_{g}^{a p p}=14 \times 10^{-3} \ln \left(\frac{N_{d}(x)}{1.4 \times 10^{17}}\right) \text { when } \mathrm{N}_{\mathrm{d}}>1.4 \times 10^{17}\left(\mathrm{~cm}^{-3}\right) \\
& \mathrm{Sp}=3 \times 10^{6}(\mathrm{~cm} / \mathrm{s}) \quad\left(\mathrm{metal}^{-}\right. \text {contacted surface) } \\
& \mathrm{S}_{\mathrm{p}}=10^{-16} \mathrm{xN}_{\mathrm{s}}(\mathrm{cm} / \mathrm{s}) \text { to } \mathrm{N}_{\mathrm{s}}>1 \times 10^{18} \mathrm{~cm}^{-3} \text { (passivated surface) }
\end{aligned}
$$

where, $\mathrm{n}_{\mathrm{io}}$ is the intrinsic carrier concentration; $\mathrm{k}$, Boltzmann constant; $\mathrm{T}$, temperature in Kelvin and $\mathrm{N}(\mathrm{x})$ is the dopant profile. As it was said previously, in this work only Gaussian profiles were considered. The apparent band gap narrowing takes into account the Fermi degeneracy when the surface doping level is higher than $1.4 \times 10^{17}$ $\left(\mathrm{cm}^{-3}\right)$. In order to simplify the calculations, the normalized hole concentration ( $\left.\mathrm{p}^{\prime}(\mathrm{x})\right)$, normalized current density $\left(\mathrm{J}^{\prime}(\mathrm{x})\right)$ and normalized carrier generation $\left(\mathrm{G}^{\prime}(\mathrm{x})\right)$ were defined (see Eqs. (4), (5) and (6)).

$$
\begin{aligned}
& p^{\prime}(x)=\frac{p(x)-p_{0}(x)}{\exp \left(\frac{q V}{k T}\right)-1} \\
& J^{\prime}(x)=\frac{J(x)}{\exp \left(\frac{q V}{k T}\right)-1} \\
& G^{\prime}(x)=\frac{G(x)}{\exp \left(\frac{q V}{k T}\right)-1}
\end{aligned}
$$

Looking for the solution for Eqs. (1) and (2), two boundary conditions were considered: one is at the depletion-region boundary $\mathrm{x}=0$ and the other is at the emitter surface $x=W_{E}$, as it can be seen in Eqs. (7) and (8).

$$
\begin{aligned}
& p(0)=p_{0}(0) \exp \left(\frac{q V}{k T}\right) \\
& J\left(W_{E}\right)=q S_{p}\left(p\left(W_{E}\right)-p_{0}\left(W_{E}\right)\right)
\end{aligned}
$$

where $S_{p}$ is surface recombination velocity.

Therefore the transport equations could be rewritten as:

$$
J^{\prime}(x)=J^{\prime}(0)-q \int_{0}^{x} \frac{p^{\prime}\left(x_{1}\right) d x_{1}}{\tau_{p}\left(x_{1}\right)}+q \int_{0}^{x} G^{\prime}\left(x_{1}\right) d x_{1}
$$

and

$$
p^{\prime}(x)=p_{0}(x)\left(1-\frac{1}{q} \int_{0}^{x} \frac{J^{\prime}\left(x_{1}\right)}{D_{p}\left(x_{1}\right) p_{0}\left(x_{1}\right)} d x_{1}\right)
$$

After some substitutions using Eqs. (9) and (10), the normalized current density and the minority carrier equilibrium concentration are obtained, though Eqs. (11) and (12) respectively. These equations are written as functions of infinite series of three coefficients $\mathrm{A}(\mathrm{x}), \mathrm{B}(\mathrm{x})$ and $\mathrm{C}(\mathrm{x})$ - see Eqs. (13), (14) and (15) respectively. An excellent accuracy was assured considering a fifth order approximation, as it is shown by A. Cuevas et al ${ }^{10}$. The emitter current density is formed by two components: saturation current density (first member) and the collected current density (second member). When the generation $\left(\mathrm{G}^{\prime}(\mathrm{x})\right)$ comes to zero, the emitter is in dark and the coefficient $\mathrm{C}^{\prime}(\mathrm{x})$ is zero too, so the emitter current density $\left(\mathrm{J}^{\prime}(0)\right)$ is equal to the 
saturation current density $\left(\mathrm{J}_{\mathrm{oE}}\right)$. The base region could be described by these expressions too, if minority carrier lifetime and mobility were considered constant and adequate expressions were used for parameters.

$$
\begin{gathered}
J^{\prime}(0)=\frac{q \int_{0}^{W_{E}} \frac{p_{0}(x)}{\tau_{p}(x)}\left(1+\sum_{i=1}^{\infty} B_{2 i}\right) d x+S_{p} p_{0}\left(W_{E}\right)\left(1+\sum_{i=1}^{\infty} B_{2 i}\left(W_{E}\right)\right)}{1+\int_{0}^{W_{E}} \frac{p_{0}(x)}{\tau_{p}(x)}\left(\sum_{i=1}^{\infty} A_{2 i-1}(x)\right) d x+S_{p} p_{0}\left(W_{E}\right) \sum_{i=1}^{\infty} A_{2 i-1}\left(W_{E}\right)} \\
-q \frac{\int_{0}^{W_{E}} G^{\prime}(x) d x+S_{p} p_{0}\left(W_{E}\right) \sum_{i=1}^{\infty} C_{2 i}^{\prime}\left(W_{E}\right)+\int_{0}^{W_{E}} \frac{p_{0}(x)}{\tau_{p}(x)} \sum_{i=1}^{\infty} C_{21}^{\prime}(x) d x}{1+\int_{0}^{W_{E}} \frac{p_{0}(x)}{\tau_{p}(x)}\left(\sum_{i=1}^{\infty} A_{2 i-1}(x)\right) d x+S_{p} p_{0}\left(W_{E}\right) \sum_{i=1}^{\infty} A_{2 i-1}\left(W_{E}\right)}
\end{gathered}
$$

and

$$
\begin{aligned}
p^{\prime}(x)=p_{0}(x)\left(1-\frac{J^{\prime}(0)}{q} \sum_{i=1}^{\infty} A_{2 i-1}(x)\right. \\
\\
\left.+\sum_{i=1}^{\infty} B_{2 i}(x)-\sum_{i=1}^{\infty} C_{2 i}(x)\right)
\end{aligned}
$$

where

$$
\begin{aligned}
& A_{2 i-1}(x)=\int_{0}^{x} \frac{d x_{1}}{D_{p}\left(x_{1}\right) p_{0}\left(x_{1}\right)} \int_{0}^{x_{1}} d x_{2} \frac{p_{0}\left(x_{2}\right)}{\tau_{p}\left(x_{2}\right)} . \\
& \quad \ldots \int_{0}^{x_{2 i-3}} d x_{2 i-2} \frac{p_{0}\left(x_{2 i-2}\right)}{\tau_{p}\left(x_{2 i-2}\right)} \int_{0}^{x_{2 i-2}} \frac{d x_{2 i-1}}{D_{p}\left(x_{2 i-1}\right) p_{0}\left(x_{2 i-1}\right)} \\
& B_{2 i}(x)=\int_{0}^{x} \frac{d x_{1}}{D_{p}\left(x_{1}\right) p_{0}\left(x_{1}\right)} \int_{0}^{x_{1}} d x_{2} \frac{p_{0}\left(x_{2}\right)}{\tau_{p}\left(x_{2}\right)} \ldots \\
& C_{2 i}^{\prime}(x)=\int_{0}^{x} \frac{d x_{1}}{D_{p}\left(x_{1}\right) p_{0}\left(x_{1}\right)} \int_{0}^{x_{1}} d x_{2} \frac{p_{0}\left(x_{2}\right)}{\tau_{p}\left(x_{2}\right)} \ldots \\
& \int_{0}^{x_{2 i-2}\left(x_{2 i-1}\right) p_{0}\left(x_{2 i-1}\right)} \int_{0}^{x_{2 i-1}} d x_{2 i} \frac{p_{0}\left(x_{2 i}\right)}{\tau_{p}\left(x_{2 i}\right)} \\
& \int_{2 i-2}^{x_{p}\left(x_{2 i-1}\right) p_{0}\left(x_{2 i-1}\right)} \int_{0}^{x_{2 i-1}} d x_{2 i} G^{\prime}\left(x_{2 i}\right)
\end{aligned}
$$

The emitter collection efficiency, expressed in (16), is the ratio between the photo-generated current density and the total emitter generated current density. The total emitter generated current density was calculated using the standard spectrum AM1.5G from ASTM 892-87.

$$
\eta_{E}=\frac{1+\frac{1}{\int_{0}^{W_{E}} d x G^{\prime}(x)}\left(S_{p} p_{0}\left(W_{e}\right) \sum_{i=1}^{\infty} C_{2 i}{ }_{2 i}\left(W_{E}\right)+\int_{0}^{W_{E}} d x \frac{p_{0}}{\tau_{p}} \sum_{i=1}^{\infty} C_{2 i}{ }_{2 i}(x)\right)}{1+\int_{0}^{W_{E}} d x \frac{p_{0}}{\tau_{p}} \sum_{i=1}^{\infty} A_{2 i-1}(x)+S_{p} p_{0}\left(W_{E}\right) \sum_{i=1}^{\infty} A_{2 i-1}\left(W_{E}\right)}
$$

In order to calculate the theoretical efficiency of a complete structure and looking for only the effect of emitter region, the base and the $\mathrm{p}^{+}$emitter region parameters have been considered constant as previously referred.

\section{Results}

\subsection{Optimization}

In order to optimize the emitter region, saturation and collected current densities were studied. The saturation current density as a function of emitter thickness with different doping levels is shown in Fig. 1, considering two kinds of surfaces, low and high surface recombination velocities. Passivated surfaces were considered having their recombination velocities dependent on $\mathrm{N}_{\mathrm{s}}\left(\mathrm{S}_{\mathrm{p}}=10^{-16}\right.$ $\mathrm{N}_{\mathrm{s}} \mathrm{cm} / \mathrm{s}$ ) while for metal-contacted surfaces and non-passivated surfaces constant values were assumed $S_{p}=3 \times 10^{6}$ $(\mathrm{cm} / \mathrm{s})$ and $\mathrm{S}_{\mathrm{p}}=2 \times 10^{5}(\mathrm{~cm} / \mathrm{s})^{4}$. A metal-contacted surface requires high doping levels $\left(\mathrm{N}_{\mathrm{s}} \cong 1 \times 10^{20} \mathrm{~cm}^{-3}\right)$ and the thickness value $(\cong 2.0 \mu \mathrm{m})$ is selected by technological constrictions. For passivated surfaces "low" doping levels ( such as $\mathrm{N}_{\mathrm{s}}=1 \times 10^{19} \mathrm{~cm}^{-3}$ and $\mathrm{N}_{\mathrm{s}}=5 \times 10^{18} \mathrm{~cm}^{-3}$ ) must be chosen.

According to this figure the thick and moderately doped passivated emitters have a low contribution for the total recombination density. For instance a homogeneous emitter with surface doping level $\mathrm{N}_{\mathrm{s}}=1 \times 10^{19}\left(\mathrm{~cm}^{-3}\right)$ and thickness $1.2(\mu \mathrm{m})$ presents $6.2 \times 10^{-14}\left(\mathrm{~A} / \mathrm{cm}^{2}\right)$ as the total emitter recombination density (passivated and non-passivated regions).

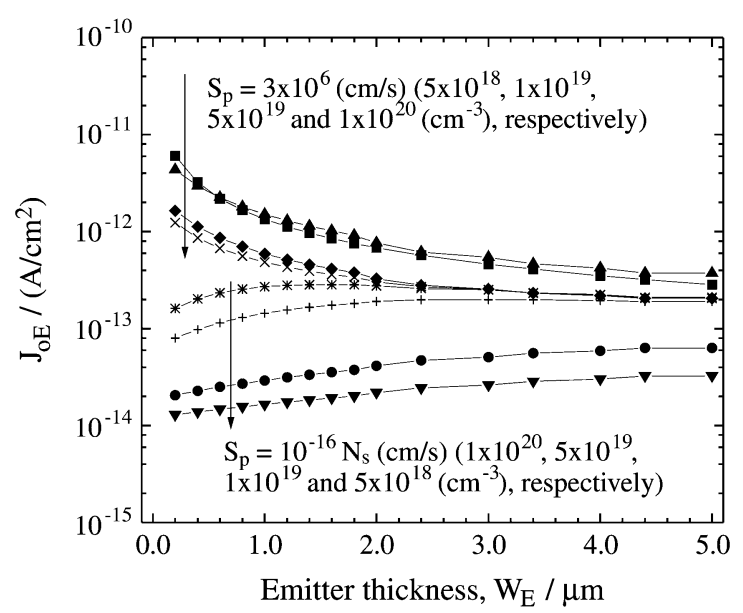

Figure 1. Emitter saturation current density $\left(\mathrm{J}_{\mathrm{OE}}\right)$ as a function of emitter thickness $\left(\mathrm{WE}_{\mathrm{E}}\right)$, considering two kinds of surfaces: metal-contacted and passivated one. 
The emitter collection efficiency, obtained from expression (16), with different doping levels as a function of emitter thickness and kinds of surfaces (passivated and non-passivated) can be observed in Fig. 2. The surface recombination velocity of non-passivated surface is $\mathrm{S}_{\mathrm{p}}=2 \times 10^{5} \mathrm{~cm} / \mathrm{s}^{4}$.

Analyzing Fig. 2, one can observe that the emitter collection efficiencies $\left(\eta_{E}\right)$ of a passivated surface are higher than non-passivated ones in most cases. According to this figure, the highly doped and shallow emitters can provide emitter collection efficiencies as high as moderately doped and thick emitters, since they have Gaussian profiles.

\subsection{Homogeneous emitters}

In order to compare the emitter effects over the complete structure, the base and $\mathrm{p}^{+}$regions have been considered constant. Thus, the output parameters of complete solar cells with homogeneous emitters have been calculated.

The short-circuit current density $\left(\mathrm{J}_{\mathrm{sc}}\right)$ as function of emitter thickness and surface doping level is shown in Fig. 3. In this figure, it can be seen that the maximums of short-circuit current density curves are approximately 38.4 $\left(\mathrm{mA} / \mathrm{cm}^{2}\right)$ to all doping levels. However, the $J_{\mathrm{sc}}$ of higher doping level emitter solar cells are more sensitive than lower doping level emitter ones when the emitter thickness increases. This occurs because the emitter collection efficiency $\left(\eta_{\mathrm{E}}\right)$ decreases significantly due to band-gap narrowing and Auger recombination effects, as it is shown in Fig. 2. As it can be seen, low doping emitters are the best choice to form this region since they provide both high current density and a wide range of optimum thickness.

The internal quantum efficiency of a complete solar cell was calculated as the ratio between the total collected current density and the total photo-generated current density for each wavelength. A complete analysis of the internal quantum efficiency for each surface doping level and the correspondent optimized thickness has been made for

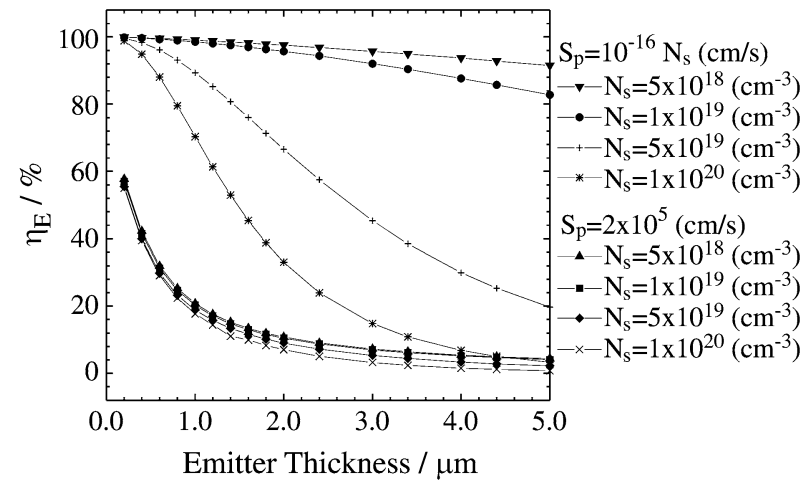

Figure 2. Emitter collection efficiency $\left(\eta_{\mathrm{E}}\right) v s$. emitter thickness, admitting different doping levels $\left(\mathrm{N}_{\mathrm{s}}\right)$ and two kinds of surfaces (passivated and non-passivated).

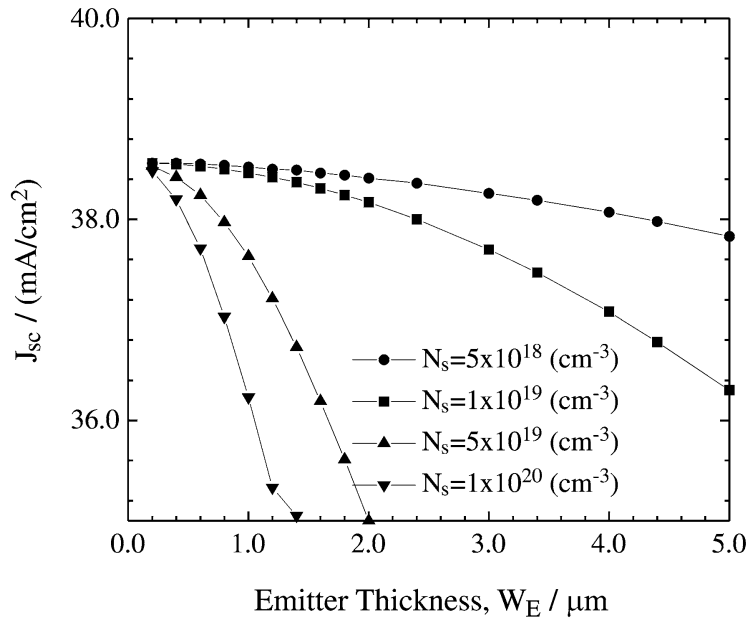

Figure 3. Solar cell short-circuit density $\left(\mathrm{J}_{\mathrm{sc}}\right)$ as a function of emitter thickness $\left(\mathrm{W}_{\mathrm{E}}\right)$, considering different doping levels (metal grid shadowing factor $\mathrm{F}_{\mathrm{m}}=3 \%$ ).

wavelengths $(\lambda=350-1100 \mathrm{~nm})$ and it has been verified that there is no significant difference among them since the emitters have Gaussian profile.

In Fig. 4 the internal quantum efficiency as function of the wavelength $(\lambda)$ is shown only for an optimized emitter with surface doping level $\mathrm{N}_{\mathrm{s}}=1 \times 10^{19}\left(\mathrm{~cm}^{-3}\right)$ and emitter thickness $\mathrm{W}_{\mathrm{E}}=1.2(\mu \mathrm{m})$. The base and BSF regions were previously considered.

According to Fig. 4 the homogeneous emitter presents a high internal quantum efficiency for the emitter wavelength range of interest $\lambda=(350-600) \mathrm{nm}$; for instance, for $\lambda=400 \mathrm{~nm}$ the internal quantum efficiency is $\mathrm{Q}_{\mathrm{i}}(\lambda) \cong 0.98$.

Figures 5 and 6 show open circuit voltage $\left(\mathrm{V}_{\mathrm{oc}}\right)$ and efficiency $(\eta)$ as functions of emitter thickness respectively, considering different emitter doping levels. It can be seen that the limiting factor to achieve high efficiencies is open circuit voltage, which is determined by the saturation current density.

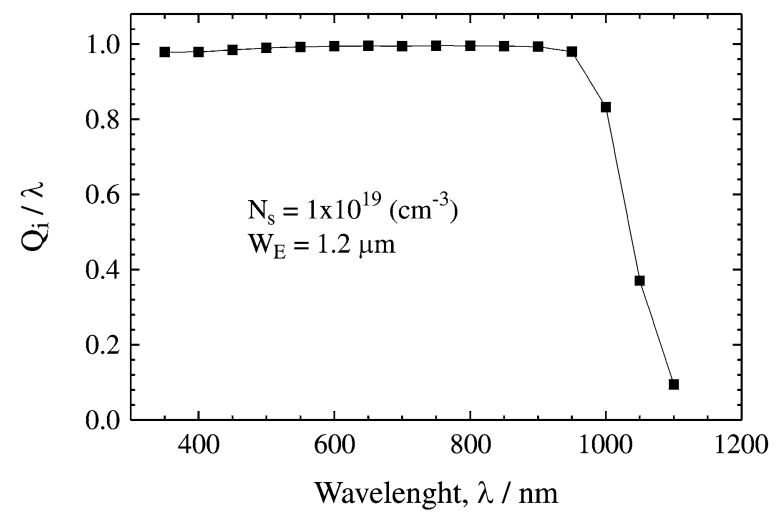

Figure 4. Solar cell internal quantum efficiency as function of wavelength. The emitter is admitted to be passivated with a surface doping level $\mathrm{N}_{\mathrm{s}}=1 \times 10^{19}\left(\mathrm{~cm}^{-3}\right)$ and $\mathrm{W}_{\mathrm{E}}=1.2(\mu \mathrm{m})$. 


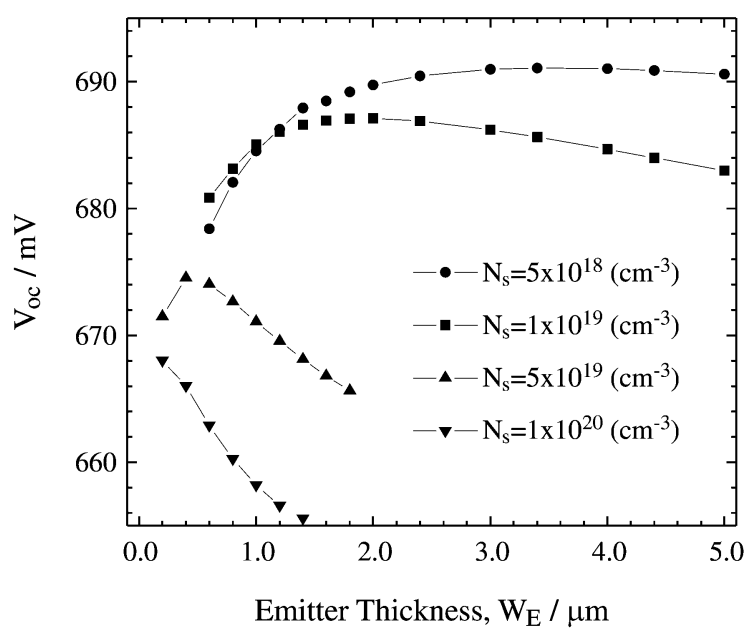

Figure 5. Solar cell open-circuit voltage $\left(\mathrm{V}_{\mathrm{oc}}\right)$ vs. emitter thickness $\left(\mathrm{W}_{\mathrm{E}}\right)$ with different doping levels (metal grid shadowing factor $\mathrm{F}_{\mathrm{m}}=3 \%$ ).

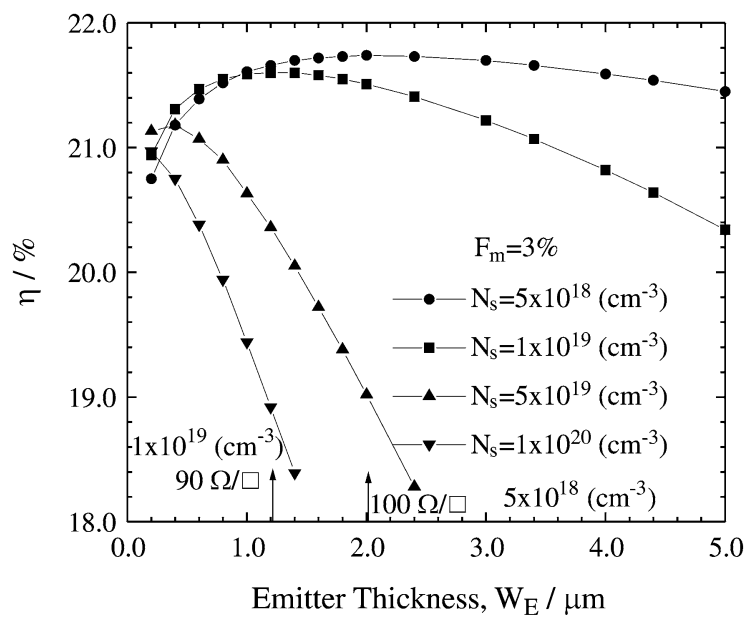

Figure 6. Solar cell efficiency $(\eta)$ as a function of emitter thickness ( $\left.W_{E}\right)$, considering different surface doping levels $\left(\mathrm{N}_{\mathrm{s}}\right)$. The arrows indicate the emitter sheet resistance.

Figure 6 shows that homogeneous emitter solar cells have their best efficiencies $(\eta \cong 21.60-21.74 \%)$ when their doping levels are $\mathrm{N}_{\mathrm{s}}=\left(1 \times 10^{19}-5 \times 10^{18}\right) \mathrm{cm}^{-3}$ and their thicknesses are (1.2-2.0) $\mu \mathrm{m}$. To simplify the calculations, the series resistance, $\mathrm{r}_{\mathrm{s}}$ has been considered as a constant, calculated to the following optimized emitter region case: surface doping level $1 \times 10^{19} \mathrm{~cm}^{-3}$ and $\cong 1 \mu \mathrm{m}$ emitter thickness (sheet resistance $\cong 100 \Omega / \square$ ). Therefore, the moderately doped and thick passivated emitters, besides requiring a simple fabrication technology, have high quality. Thus, being of interest for industrial application.

\subsection{Non-homogeneous emitters}

Like it was made in the former case, the output parameters for complete solar cell were analysed. Non-homogeneous emitters are made up of two regions: a passivated one (moderately doped) and a metal-contacted one (highly doped). By examining Fig. 1, it can be seen that to reach low saturation current density $\left(\mathrm{J}_{\mathrm{oE}}\right)$ under metal-contacted surface emitters, this region must be highly doped. In this case, the thicker the emitter is, the lower $\mathrm{J}_{\mathrm{OE}}$ is. So in order to optimize non-homogeneous emitters, the surface doping level of $\mathrm{N}_{\mathrm{s}}=1 \times 10^{20} \mathrm{~cm}^{-3}$ and $2 \mu \mathrm{m}$ thickness (due to technological constrictions) were chosen. Short-circuit current densities $\left(\mathrm{J}_{\mathrm{sc}}\right)$ are the same as homogeneous emitter solar cell ones, since it was considered the same metal grid shadowing factor $\mathrm{F}_{\mathrm{m}}$ (3\%) for both kinds of emitters. Opencircuit voltage $\left(\mathrm{V}_{\mathrm{oc}}\right)$ behavior of non-homogeneous emitter solar cells is quite different of homogeneous emitter solar cells - compare Figs. 5 and 7. Non-homogeneous emitters have their maximum $\mathrm{V}_{\mathrm{oc}}$ higher than the homogeneous ones.

Their maximum efficiencies are $(\eta \cong 21.82-21.92 \%)$ with $\mathrm{N}_{\mathrm{s}}=1 \times 10^{19}-5 \times 10^{18}\left(\mathrm{~cm}^{-3}\right)$ and $(1.2-2.0)(\mu \mathrm{m})$ thick-

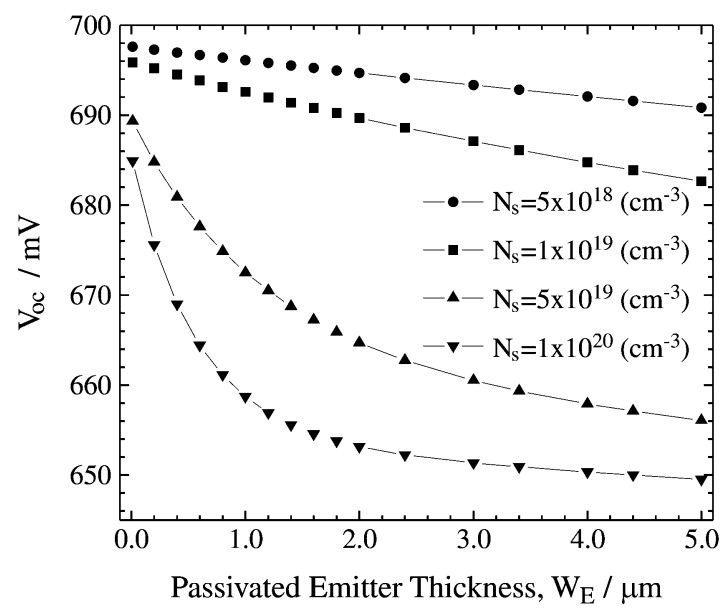

Figure 7. Solar cell open-circuit voltage as a function of passivated emitter thickness $\left(\mathrm{W}_{\mathrm{E}}\right.$ ), considering different doping levels (metal grid shadowing factor $\mathrm{Fm}_{\mathrm{m}}=3 \%$ ).

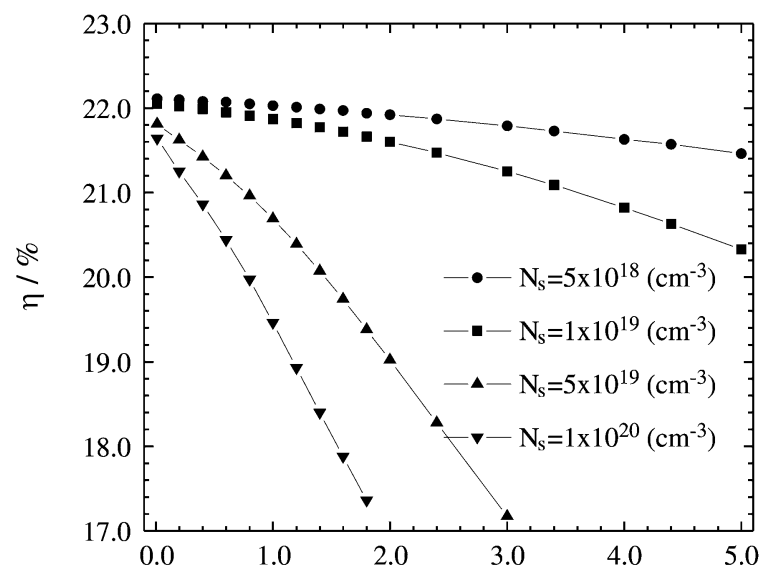

Passivated Emitter Thickness, $\mathrm{W}_{\mathrm{E}} / \mu \mathrm{m}$

Figure 8. Solar cell efficiency $(\eta)$ as a function of passivated emitter

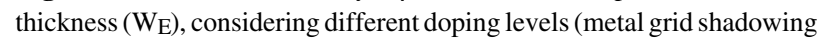
factor $\mathrm{F}_{\mathrm{m}}=3 \%$ ). 
Table 2. Comparison between the optimum output electrical parameters for homogeneous and non-homogeneous emitter solar cells.

\begin{tabular}{lcccccc}
\hline Techn. & $\mathrm{N}_{\mathrm{s}}\left(\mathrm{cm}^{-3}\right)$ & $\mathrm{W}_{\mathrm{E}}(\mu \mathrm{m})$ & $\mathrm{J}_{\mathrm{sc}}\left(\mathrm{mA} / \mathrm{cm}^{2}\right)$ & $\mathrm{V}_{\mathrm{oc}}(\mathrm{mV})$ & $\eta(\%)$ & $\mathrm{J}_{\mathrm{oE}}\left(\mathrm{A} / \mathrm{cm}^{2}\right)$ \\
\hline Homog. & $1 \times 10^{19}$ & 1.2 & 38.42 & 686.0 & 21.6 & $6.2 \times 10^{-14}$ \\
& $5 \times 10^{18}$ & 2.0 & 38.42 & 689.7 & 21.7 & $4.7 \times 10^{-14}$ \\
Non-Homog. (metal-contacted region) & $1 \times 10^{20}$ & 2.0 & - & - & - & - \\
Non-Homog. (passivated region) & $1 \times 10^{19}$ & 1.2 & 38.42 & 692.0 & 21.8 & $3.9 \times 10^{-14}$ \\
& $5 \times 10^{18}$ & 2.0 & 38.42 & 694.7 & 21.9 & $3.0 \times 10^{-14}$ \\
\hline
\end{tabular}

ness for passivated surface, as it can be seen in Fig. 8. Since the approximation of a constant $\left(\mathrm{r}_{\mathrm{s}}\right)$ has been made, efficiencies related to emitter sheet resistances higher than $100 \Omega / \square$ are overestimated.

Table 2 shows a comparison between the optimum electrical output parameters for homogeneous and non-homogeneous emitter solar cells, and the total emitter recombination as well.

It can be seen that the efficiencies in general are better for non-homogeneous emitter solar cells, the maximum efficiencies related to each different doping level are slightly higher, about $0.20(\%)$, than homogeneous ones.

As it has been commented previously, the open-circuit voltage is the limiting factor to reach higher efficiencies. When the kind of emitter is changed from homogeneous into non-homogeneous the emitter recombination current density decreases from $6.2 \times 10^{-14}\left(\mathrm{~A} / \mathrm{cm}^{2}\right)$ to $3.9 \times 10^{-14}$ $\left(\mathrm{A} / \mathrm{cm}^{2}\right)$, resulting in increase of approximately $1 \%$ in the open-circuit voltage for a passivated region with $\mathrm{N}_{\mathrm{s}}=1 \times 10^{19}\left(\mathrm{~cm}^{-3}\right)$ and $\mathrm{W}_{\mathrm{E}}=1.2(\mu \mathrm{m})$. Therefore, the nonhomogeneous emitter solar cells are still responsible for the record efficiency laboratory solar cells, having more flexibility to obtain good ohmic contacts. However, the complexity of the involved technology points the attention to the studies of Gaussian profile homogeneous emitter ones and their applications.

\section{Conclusions}

In this work a theoretical optimization of highly doped n-type region with Gaussian profile and complete solar cells have been made as functions of surface recombination velocity, emitter thickness and surface doping level. Furthermore, updated internal parameters have been used to take into account recent published changes. Considering these new conditions, homogeneous and non-homogeneous were studied. Homogeneous emitter solar cells show the maximum range of solar cell efficiency, $\eta=21.60$ $21.74 \%$ for $\mathrm{N}_{\mathrm{s}}=1 \times 10^{19}-5 \times 10^{18} \mathrm{~cm}^{-3}$ with $1.2-2.0 \mu \mathrm{m}$ emitter thickness range, corresponding to emitter sheet resistances $90-100 \Omega / \square$ respectively. Non-homogeneous emitter solar cells provide their best efficiencies $\eta=(21.82-$ $21.92 \%$ ) with surface doping levels $\mathrm{N}_{\mathrm{s}}=1 \times 10^{20} \mathrm{~cm}^{-3}$ with $2.0 \mu \mathrm{m}$ thickness under metal-contacted surface and
$\mathrm{N}_{\mathrm{s}}=1 \times 10^{19}-5 \times 10^{18} \mathrm{~cm}^{-3}$ with $(1.2-2.0) \mu \mathrm{m}$ thickness respectively under passivated surface. The non-homogeneous emitter efficiencies are slightly better $(0.20 \%)$ than homogeneous one, this relatively small difference is due to the fact that recombination in the base region also contributes to limit the cell voltage. Despite non-homogeneous emitters are more complex, they are still relevant for ultra high efficiency solar cells. However, in practical silicon solar cells, the difference between the two kinds of emitters vanishes almost completely; since the contribution from the base region is still larger than that assumed in this paper, non-homogeneous provide more flexibility to obtain good ohmic contacts. The use of optimized homogeneous emitters with screen-printing metallization still awaits innovative ideas and experimental demonstration.

\section{Acknowledgments}

This work was supported by FAPESP under contract $\mathrm{n}^{\mathrm{o}} 95 / 09435-0$ and by Rhae/CNPq under contract $\mathrm{n}^{\circ} 610157 / 94$.

\section{References}

1. Cuevas, A.; Balbuena, M.A.; Galloni, R. Conf. Rec. $19^{\text {th }}$ IEEE Photovoltaic Specialists Conference, New Orleans, p. 918-924, May 1987.

2. Cuevas, A.; Balbuena, M. $20^{\text {th }}$ IEEE Photovoltaic Specialists Conference, v. 1, p. 429-434, 1988.

3. Aberle, A.; Warta, W.; Knobloch, J.; Vob, B. $21^{\text {st }}$ IEEE Photovoltaic Specialists Conference, v. 1, p. 233-238, 1990.

4. Cuevas, A.; Basore, P.A.; Girouit-Matlakoski, G.; Dubois, C. J. Appl. Phys., v. 80, n. 6, p. 3370-3375, 1996.

5. Park, J.; Neugroschel, A.; Lindholm, F.A. IEEE Transactions on Electron Devices, v. ED-33, n. 2, p. 240-248, 1986.

6. Bisschop, F.J.; Verholf, L.A.; Sinke, W.C. IEEE Transactions on Electron Devices, v. 37, n. 2, p. 358-363, 1991.

7. Lolgen, P.; Leguijt, C.; Eikelboom, J.A.; Steman, R.A.; Sinke, W.C.; Verhoef, L.A.; Alkemade, P.F.A.; Algra, E. $23^{\text {rd }}$ IEEE Photovoltaic Specialists Conference, p. 236-242, 1993.

8. Green, M.A. Solar Cells: Operating Principles, Technologyand System Applications, Englewood Cliffs: Prentice-Hall, p. 78, 1982.

9. Sánchez, E.; Araújo, G.L. Solar Cells, v. 20, p. 1-11, 1987.

10. Cuevas, A.; Merchán, R.; Ramos, J.C. IEEE Transactions on Electron Devices, v. 40, n. 6, p. 1181-1183, 1993. 